\title{
APENDAGITE EPIPLÓICA: aspectos clínicos e radiológicos
}

\author{
Gustavo Pignaton de FREITAS, Adriana de Almeida BORGES, Renato MENDONÇA, \\ Cláudia RIBEIRO e Maria Chiara CHINDAMO
}

\begin{abstract}
RESUMO - Apendagite epiplóica é uma doença inflamatória abdominal incomum. Foram avaliados, retrospectivamente, os prontuários de 44 pacientes com diagnóstico de apendagite epiplóica atendidos no Hospital Barra D’Or, Rio de Janeiro, RJ, no período entre fevereiro de 2005 e setembro de 2006, sendo $82 \%$ homens e $18 \%$ mulheres, com média de idade de 44,7 anos. Buscou-se caracterizar o quadro clínicolaboratorial e radiológico desses pacientes. As alterações laboratoriais mais freqüentes foram piúria e leucocitose, cada uma presente em 5\% dos casos. O diagnóstico foi feito por tomografia computadorizada de abdome com achado de lesão ovóide em cólon descendente em $52 \%$ dos pacientes. A resolução do quadro clínico foi obtida com tratamento conservador.

DESCRITORES - Dor abdominal. Tecido adiposo. Tomografia computadorizada espiral.
\end{abstract}

\section{INTRODUÇÃO}

A apendagite epiplóica (AE) é uma condição clínica incomum, benigna e auto-limitada. Resulta da torção ou trombose venosa espontânea das veias que drenam os apêndices epiplóicos. Manifesta-se por dor abdominal aguda localizada principalmente em quadrante inferior esquerdo (QIE). O diagnóstico se faz por tomografia computadorizada (TC) de abdome. O tratamento é conservador.

\section{MÉTODOS}

Pacientes atendidos no Hospital Barra D’Or (HBD), Rio de Janeiro, RJ, entre fevereiro de 2005 e setembro de 2006, com quadro de dor abdominal e submetidos a avaliação clínico-laboratorial e a métodos de imagem (tomografia computadorizada helicoidal). Foram avaliados, retrospectivamente, boletins de atendimento do hospital e verificados resultados de exames complementares apenas de pacientes com diagnóstico tomográfico de $\mathrm{AE}$ atendidos no HBD. Buscou-se identificar dados epidemiológicos e definir aspectos relacionados à localização, tempo de evolução e tratamento da enfermidade naquela instituição. Buscou-se definir as alterações laboratoriais mais encontradas e descrever características de imagem tomográfica da apendagite (localização e tamanho).

\section{RESULTADOS}

Foram avaliados 44 pacientes com diagnóstico de AE, $82 \%$ homens e $18 \%$ mulheres, com idade variando entre 20 e 84 anos e média de idade de 44,7 anos.
A apresentação clínica mais comum foi dor abdominal de moderada intensidade localizada em QIE em 93\% dos casos. A dor em mesogástrio foi observada em $2 \%$ dos pacientes, suscitando o diagnóstico diferencial de pancreatite aguda; dor hipogástrica foi relatada em $5 \%$ dos casos. O tempo de evolução da dor abdominal, anterior ao diagnóstico definitivo, variou de 1 a 5 dias, com mediana da duração de 3 dias.

As alterações laboratoriais mais freqüentes foram: piúria discreta e leucocitose, cada uma presente em $5 \%$ dos pacientes. A maioria deles, representando $81 \%$ dos casos, não apresentou quaisquer alterações laboratoriais. Nos demais casos, não havia registros de exames laboratoriais.

O diagnóstico definitivo foi feito por TC de abdome com achado de imagem ovalar com densidade de gordura e centro radioluscente (Figuras 1 e 2). A topografia mais freqüente foi a de cólon descendente em 52\% dos pacientes, seguido pelo sigmóide em $30 \%$ e cólon transverso em $2 \%$. As lesões ovóides observadas na TC de abdome mediam entre 1,4 e $4,1 \mathrm{~cm}$, com média de $2,4 \mathrm{~cm}$. Observou-se espessamento da gordura perilesional em todos os pacientes (Figura 2).

A maioria dos pacientes, $62 \%$ dos casos (27/44), foi submetida a tratamento em ambulatório com analgésicos e antiinflamatórios. A prescrição de antibióticos foi praticada em $36 \%$ dos pacientes. Os medicamentos mais comumente indicados foram amoxicilina-clavulanato em $25 \%$ (4/16) e ciprofloxacina isolada ou associada ao metronidazol em $75 \%$ (12/16). Um paciente foi internado e submetido a tratamento cirúrgico com ressecção e drenagem de abcesso em sigmóide. Não houve seguimento após alta hospitalar.

Serviços de ${ }^{1}$ Clínica Médica e de ${ }^{2}$ Radiologia do Hospital Barra D'OR, Rio de Janeiro, RJ.

Endereço: Dr. Gustavo Pignaton de Freitas - Av. Ayrton Senna, - Barra da Tijuca - 22775-001 - Rio de Janeiro, RJ. E-mail : guspignaton@gmail.com 


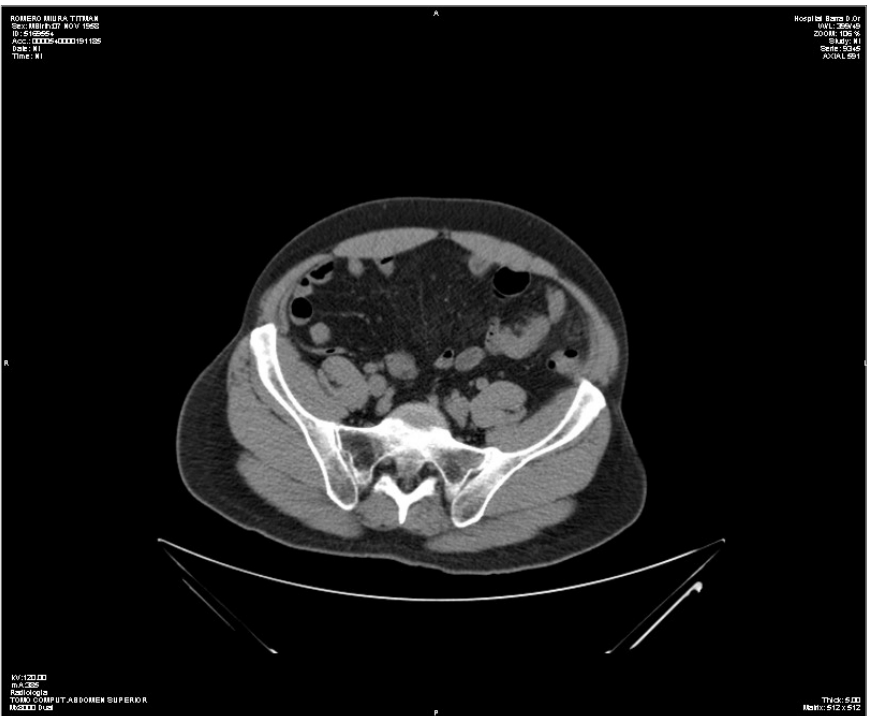

FIGURA 1. TC abdome com imagem ovalar com densidade de gordura e centro radioluscente em cólon esquerdo

\section{DISCUSSÃO}

A apendagite é uma condição clínica benigna, que ocorre secundariamente à torção ou trombose venosa espontânea das veias que drenam os apêndices epiplóicos ${ }^{(5)}$. A sinonímia é variada e inclui: apendicite epiplóica, apendagite, epiploitite hemorrágica, epiplopericolite. Atinge indivíduos entre a segunda e quinta décadas de vida, com incidência similar entre homens e mulheres ${ }^{(3)}$.

Os apêndices epiplóicos foram primeiramente descritos por Vesalius em $1543^{(2)}$. No entanto, a entidade apendagite só foi reconhecida por Linn, em $1956^{(2)}$.

Os apêndices omentais são projeções da superfície externa do cólon, repletas de gordura, recobertas por serosa e projetando-se na cavidade peritonial. Aproximadamente 50 a 100 apêndices estão presentes ao longo do cólon, porém são mais abundantes e proeminentes no cólon transverso e sigmóide. Seu tamanho médio é de $3 \mathrm{~cm}$, variando de 0,5 a $5 \mathrm{~cm}$, embora possa ocasionalmente alcançar até $15 \mathrm{~cm}^{(3)}$. São mais numerosos e de maior tamanho em indivíduos obesos e naqueles com história de emagrecimento recente. Sua função é similar à do grande omento, constituindo um mecanismo de defesa e proteção.

A apresentação clínica habitual é de dor abdominal aguda localizada em quadrante inferior esquerdo, em paciente com bom estado geral e afebril. No entanto, pode mimetizar quadro de abdome agudo, levando ao diagnóstico incorreto de apendicite ou de diverticulite agudas.

A análise laboratorial se caracteriza pela contagem de leucócitos e velocidade de hemossedimentação normais ou pouco elevados. Não há relatos de alterações urinárias. $\mathrm{Na}$ presente amostra houve $5 \%$ de alterações do sedimento urinário, definidas como contagem de piócitos superior a 5 por

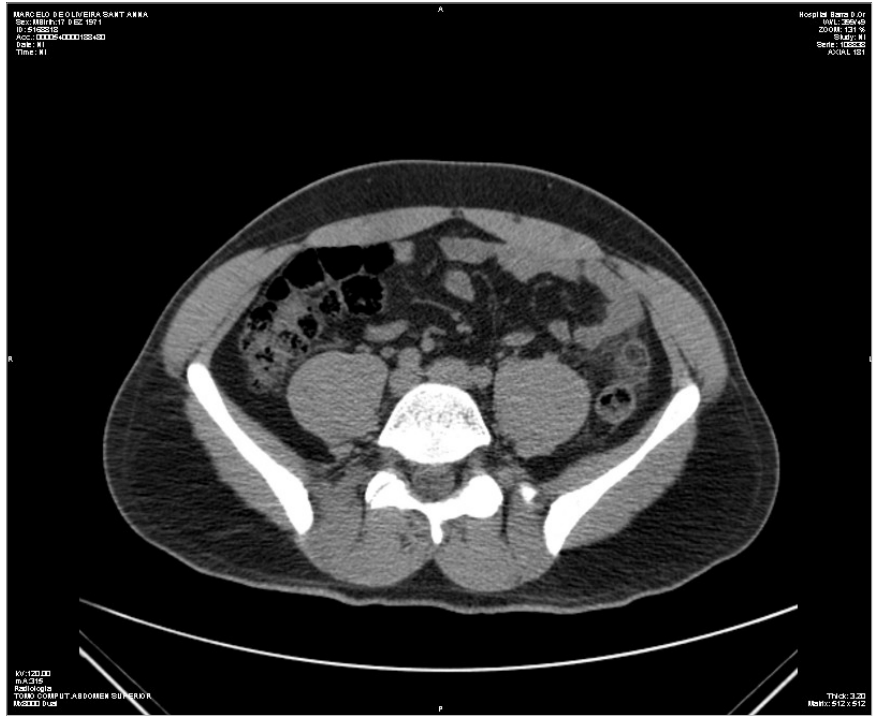

FIGURA 2. TC abdome com imagem ovalar com densidade de gordura e centro radioluscente em cólon esquerdo

campo em homens, de acordo com a ABNT 2005. Não foram consideradas alterações inferiores a este patamar. Houve 5\% de leucocitose nos pacientes estudados, definida com contagem de leucócitos superior a $11.000 / \mathrm{mm}^{3}$. O relato da literatura de discreta leucocitose em pacientes com AE corrobora o achado da presente casuística(6).

Antes do advento da $\mathrm{TC}$, o diagnóstico era realizado intra-operatoriamente. A primeira descrição tomográfica de AE é atribuída a Danielson, em $1986^{(3)}$. Atualmente, o diagnóstico se faz por TC de abdome, com o achado de massa paracólica, ovalar, de 1 a $5 \mathrm{~cm}$, com densidade de gordura, acompanhando-se de espessamento do revestimento peritonial e atenuação da gordura periapendicular. As lesões ovalares observadas na presente casuística revelaram diâmetros entre 1,4 e 4,1 cm, compatíveis com as dimensões descritas na literatura. Há relatos de diagnóstico por ultra-sonografia (US) e ressonância nuclear magnética (RNM). Na US de abdome pode-se evidenciar lesão expansiva ovóide hiperecóica, não-compressíva, com halo hipoecóico. Apesar de ser bom método diagnóstico, a precisão da US depende da experiência do radiologista, do tipo de equipamento e do tipo físico do paciente, com pior rendimento em obesos. Já a RNM, apesar da elevada resolução de imagem, tem seu uso limitado pelo alto custo e pela menor disponibilidade ${ }^{(1,2,3,5,6)}$.

A lista de diagnósticos diferenciais é extensa e inclui apendicite, diverticulite, doenças de vesícula biliar, ruptura de cisto ovariano, torção de ovário, gravidez ectópica, câncer de cólon, abcesso, ileíte por Crohn, adenite mesentérica, cisto de úraco. Do ponto de vista estritamente tomográfico, outras condições podem mimetizar apendagite, entre elas: infarto omental, paniculite mesentérica e processos inflamatórios agudos primários ou secundários (apendicite ou diverticulite) $)^{(4)}$. 
O tratamento é conservador, em ambulatório e dispensa o uso de antibióticos ou tratamento cirúrgico. Consiste na administração de analgésicos e antiinflamatórios, com a melhora completa dos sintomas em torno de 3 a 14 dias. O diagnóstico incorreto pode levar a intervenções desnecessárias, sejam elas hospitalizações, antibioticoterapia ou até mesmo cirurgias. Na amostra estudada, $36 \%$ dos pacientes recebeu tratamento com antibióticos orais ou parenterais, enquanto que um paciente foi submetido a cirurgia.

\section{CONCLUSÃO}

A AE é uma doença inflamatória, incomum, de bom prognóstico. No estudo realizado houve predomínio de homens, na quinta década de vida. A manifestação clínica mais observada foi a dor abdominal em quadrante inferior esquerdo. O diagnóstico foi estabelecido por TC de abdome. A lista de possíveis diagnósticos diferenciais é extensa, variando de acordo com a localização da AE. O tratamento conservador leva à resolução completa do quadro na maioria dos casos.

Freitas GP, Borges AA, Mendonça R, Ribeiro C, Chindamo MC. Epiploic appendagitis: clinical and radiological aspects. Arq Gastroenterol. 2008;45(2):163-5.

ABSTRACT - Epiploic appendagitis is an uncommon inflammatory abdominal disease. Data of 44 patients with a clinical diagnosis of appendagitis were retrospectively evaluated regarding laboratory and imaging findings. They were admitted to Barra D’Or Hospital, Rio de Janeiro, RJ, from February 2005 to September 2006. Eighty-two percent were male and 18 were female, with median age of 44.7 years. The most frequent laboratory findings were hematuria in urinalysis and leucocitosis, presenting in $5 \%$ of cases each. Diagnosis was obtained through computed tomography showing paracolic oval lesions, mainly over the descending colon in $52 \%$ of patients. Patients were treated with analgesics and anti-inflammatory in an outpatient basis. Recovery was uneventful under conservative treatment.

HEADINGS - Abdominal pain. Adipose tissue. Tomography, spiral computed.

\section{REFERÊNCIAS}

1. Kantarci M, Duran C, Sirvanci M. Images of interest. Gastrointestinal: epiploic appendagitis. J Gastroenterol Hepatol. 2005;20:482.

2. Legome EL, Sims C, Rao PM. Epiploic appendagitis: adding to the differential of acute abdominal pain. J Emerg Med. 1999;17:823-6.

3. Melo AS, Moreira LB, Pinheiro RA, Noro F, Alves JR, Machado BB. Apendicite epiplóica: aspectos na ultra-sonografia e na tomografia computadorizada. Radiol Bras. 2002;35:171-4.
4. Singh AK, Gervais DA, Hahn PF, Sagar P, Mueller PR, Novelline R. Acute epiploic appendagitis and its mimics. Radiographics. 2005;25:1521-34.

5. Varela U, Fuentes MV, Rivadeneira R. Procesos inflamatorios del tejido adiposo intraabdominal, causa no quirurgica de dolor abdominal agudo: hallazgos en tomografia computada. Rev Chil Radiol. 2004;10:28-34.

6. Vinson DR. Epiploic appendagitis: a new diagnosis for the emergency physician. Two cases report and a review. J Emerg Med. 1999;17:827-32.

Recebido em 9/8/2007. Aprovado em16/10/2007 